\title{
O NÚCLEO DE ESTUDOS E PESQUISA SOBRE A DIVERSIDADE ÉTNICO- RACIAL/NEDER E AS IMPLEMENTAÇÕES DAS LEIS 10.639/2003 E 11.645/2008 NA REDE MUNICIPAL DE ENSINO DE MACEIÓ
}

\author{
THE NUCLEUS OF STUDIES AND RESEARCH ON DIVERSITY ÉTNICO-RACIAL/NEDER AND THE \\ IMPLEMENTATIONS OF LAWS 10.639/2003 AND 11.645/2008 IN THE MUNICIPAL NET OF MACEIÓ \\ EDUCATION
}

Marcus Swell Brandão Menezes

Rosário de Fátima da Silva*

\begin{abstract}
RESUMO:
Este texto apresenta parte dos resultados da ação do Núcleo de Estudos e Pesquisa sobre a Diversidade ÉtnicoRacial (NEDER) na rede municipal de ensino de Maceió, na aplicação das Leis 10.639/2003 e 11.645/2008. 0 intuito é apontar os desafios pedagógicos e políticos da luta anti-racista, tendo em vista a histórica intolerância existente no Brasil e na sociedade alagoana. Espera-se, no exemplo apresentado, apontar caminhos de articulação entre educadores e agentes dos movimentos sociais.
\end{abstract}

PALAVRAS-CHAVE: NEDER; Leis 10.639/2003 e 11.645/2008; Relações étnico-raciais.

\section{ABSTRACT:}

This text presents part of the results of the action of the Nucleus of Studies and Research on Diversity Ethnic-Racial (NEDER) in the municipal net of education of Maceio, in the application of Laws 10,639/2003 and 11.645/2008. Intention is to point the pedagogical challenges and politicians of the fight anti-racist, in view of the historical existing intolerance in Brazil and the alagoana society. One expects, in the presented example, to point ways of joint between educators and agents of the social movements.

KEYWORDS: NEDER; Laws 10,639/2003 and 11.645/2008; Ethnic-racial relations.

\section{INTRODUÇÃO}

Considerando a diversidade da nossa sociedade como resultado da miscigenação, calar diante do racismo, é negar a importância dos(as) negro(as), índios(as) no processo de construção do

Licenciado em História pela Universidade Federal de Alagoas - UFAL; Especialista em Geo-História pela Universidade Federal de Alagoas - UFAL; Pós-Graduando em Gestão Pública Municipal pela Universidade Federal de Alagoas. Membro do Núcleo de Estudos e Pesquisas sobre a Diversidade Étnico-Racial NEDER/SEMED/Maceió - Alagoas; Sócio da Associação Nacional dos Professores de História - ANPUH/AL e Professor de História das Redes Municipal de Maceió e do Estado de Alagoas.

(e-mail: swellbrandao@hotmail.com); Graduada em Pedagogia pela Universidade Federal de Alagoas (UFAL); Coordenadora do Núcleo de Diversidade Étnico-Racial, da Secretaria Municipal de Educação de Maceió; e formadora da área de conhecimento de Ensino Religioso dos professores da Rede.

(e-mail: rosario.silva2004@ig.com.br) 
Brasil. Debruçando o olhar sobre a discriminação étnico-racial, nós enquanto técnicos pedagógicos das diversas áreas do conhecimento, estamos numa caminhada pedagógica de ampliação dos nossos horizontes, possibilitando um repensar da nossa prática pedagógica diante da problemática do racismo que agride os Direitos Humanos, numa sociedade marcada pelo preconceito e a intolerância que impede a igualdade entre as diferenças.

Segundo o documento "Política Nacional de Promoções da Igualdade Racial" da Secretaria Especial de Políticas de Promoções da Igualdade Racial (SEPPIR), há uma equação a ser enfrentada em nosso país, 510 anos de nação, 400 anos vividos sob o regime do escravismo e apenas 122 anos de liberdade, pelo menos do ponto de vista formal, para mais da metade da população. 0 mesmo documento nos trás a informação de que no período do escravismo e nos anos que se seguiram na pósabolição, é marcado pela mais absoluta omissão estatal em face das desigualdades e da discriminação racial, contabiliza-se uma trajetória de exclusão social e econômica dos descendentes africanos.

Historicamente estamos vivendo um momento ímpar no que se refere à discussão da diversidade étnico-racial, da intensificação das ações baseadas em etnias. Essa efervescência teórica aplicada aos debates sociais favorece significativamente no redimensionamento que se pretende dar à formação continuada de professores da Rede Municipal de Ensino.

Os Parâmetros Curriculares Nacionais (BRASIL: 1997) que apresentam como um dos temas transversais, o da Pluralidade Cultural, suscitam preocupações ao proporem uma identidade nacional denominada brasilidade não questionando as bases etnocêntricas desta constituição dissemina a crença de que o conhecimento, por si só, transformará as bases racistas da sociedade. Apresentando propostas apenas no campo teórico (novos conteúdos) e moral (empatia e solidariedade aos que sofrem discriminação) que não rumam para alteração da estrutura educacional.

As leis 10639/03 e 11.645/08 alteram a LDBEN e trás a obrigatoriedade do ensino da história e cultura afro-brasileira no currículo escolar do Ensino Fundamental e Médio e das ações afirmativas constantes nas "Diretrizes Curriculares Nacionais para Educação das Relações Étnico-Raciais e para o Ensino da História e Cultura Afro-brasileira, Africana e Indígena.

Não obstante, e em conseqüência dessa movimentação de reivindicações históricas, crescem, consideravelmente, os projetos de cunho étnico-racial nas escolas. Palco institucional que apresenta professoras, professores, alunas e alunos como sujeitos histórico-sociais, cuja atuação é na perspectiva da superação das práticas racistas e excludentes.

A escola não é um campo neutro que recebe seus atores separados de suas contradições, seus valores, maneira de ver e explicar o mundo. As diferentes concepções acerca de negritude, racismo, discriminação e preconceito delineiam o desenvolvimento do projeto da escola. $E$, neste movimento, elementos da cultura dominante são adotados, na maioria das vezes, como uma forma de sobreviver em 
meio a tantos conflitos e tentativas de destruição da imagem negra. Essa condição é, ao mesmo tempo, uma denúncia do quanto o racismo está fortalecido em nossa sociedade.

É nesta perspectiva que o Núcleo de Estudos e Pesquisa sobre a Diversidade ÉtnicoRacial/NEDER vem desenvolvendo ações de Formação Continuada, de modo interdisciplinar, integrando as diversas áreas de conhecimento, bem como todas as modalidades de ensino desta Rede Municipal de Educação.

A introdução da interdisciplinaridade implica simultaneamente numa transformação profunda da Pedagogia e num novo tipo de formação de professores. Passa-se de uma relação pedagógica baseada na transmissão do saber de uma disciplina ou matéria - que se estabelece segundo um modelo hierárquico linear - a uma relação pedagógica dialógica onde a posição de um é a posição de todos. Nesses termos, o professor passa a ser o atuante, o crítico, o animador por excelência. Sua formação, substancialmente modifica-se: ao lado de um saber especializado (nisto concorreriam todas as disciplinas que pudessem dotá-lo de uma formação geral bastante sedimentada), a partir, portanto de uma iniciação comum, múltiplas opções poderão ser-lhe oferecidas em função da atividade que irá posteriormente desenvolver.

(...) Precisa receber também uma educação para a sensibilidade, um treino na arte de entender e esperar e um desenvolvimento no sentido da criação e imaginação. A interdisciplinaridade será possível pela participação progressiva num trabalho de equipe que vivencie esses atributos e que vá consolidando essa atitude (FAZENDA, 1978: 48-9).

Na educação brasileira, a ausência de uma reflexão sobre as relações raciais no planejamento escolar tem impedido a promoção de relações interpessoais respeitáveis e igualitárias entre os agentes sociais que integram o cotidiano da escola. 0 silêncio sobre o racismo, o preconceito e a discriminação raciais nas diversas instituições educacionais contribui para que as diferenças de fenótipo entre negros e brancos sejam entendidas como desigualdades naturais. Mais do que isso, reproduzem ou constroem os negros como sinônimos de seres inferiores.

\section{A DIVERSIDADE ÉTNICO-RACIAL PROMOVENDO A INTERDISCIPLINARIDADE NA ESCOLA}

O curso foi estruturado dentro do Projeto de Formação Continuada desta Secretaria, sendo organizado em três etapas: cursos de 60h, seminário de $40 \mathrm{~h}$ e oficinas de $20 \mathrm{~h}$. 
Durante a realização do curso, foi subsidiado e fomentado o direcionamento das ações que estão sendo realizadas nas escolas da Rede, garantindo a implementação das políticas pedagógicas voltadas para a reorientação curricular, a partir do reconhecimento das raízes do passado histórico brasileiro, que levaram à exclusão social de negros e índios no exercício de sua cidadania.

Este projeto e suas ações foram executados em 73 escolas da Rede Municipal atendendo a 365 professores e 51.334 estudantes (dados de 2005) do Ensino Fundamental em parceria com NEDER/ SEMED e MEC.

A metodologia utilizada fundamentou-se na articulação entre teoria e valorização do saber do professor, tendo como base sua experiência e interação como processo, através da leitura e discussão de textos, análise de filmes, palestras com especialistas da área, aulas de campo, oficinas pedagógicas, organização de atividades pedagógicas interdisciplinares e socialização de atividades desenvolvidas nas escolas.

As Temáticas abordadas foram: 1) Cursos: Currículo e relações Étnico-Raciais; A Lei 10.639/03 e o Currículo; A Escola e o Currículo; O Currículo da Escola Zumbi dos Palmares; Abordagens da historiografia; Religiosidade Afro-Brasileira. 2) Seminário: Ações afirmativas a uma educação anti-racista: A Escola respeitando sua diversidade na construção de Identidades. 3) Oficinas Pedagógicas: Práticas pedagógicas na construção da identidade; Quilombos; A religiosidade afro-brasileira; Reconhecimento e valorização da arte da matriz africana como patrimônio cultural brasileiro; Influência das línguas africanas no português brasileiro e Análise e Reflexões acerca de novos materiais didáticos ligados a área afrocultural.

A primeira temática do Curso foi trabalhada pelo Clébio Correia de Araújo mestre em Educação Brasileira. Durante a formação o professor destacou a relação da educação com o Currículo Escolar. Como trabalhar com as diferenças, como este diferente está sendo pensando, o que precisamos transformar em relação ao Currículo. A importância dessa temática no início do curso foi indispensável para que os professores fizessem uma retrospectiva de suas práticas pedagógicas, daí a necessidade de trabalhar visando o respeito pelo outro, principalmente quando se refere à Diversidade Étnico-Racial porque o modelo de sociedade é excludente, a cultura é sempre negada, principalmente quando está ligada a esta temática. Ainda nessa primeira etapa foram trabalhadas as Abordagens da Historiografia com o professor Zezito de Araújo, Mestre em História do Brasil. Este professor tem uma vasta caminhada na área, o mesmo destacou durante a formação a História da África, sua formação, construção e suas contribuições na Formação do povo brasileiro. Houve destaque também às Culturas e Civilizações, grupos sociais existentes na África, a divisão das civilizações, todos esses aspectos foram aprofundados com os professores cursistas. 
Vale ressaltar que nesta primeira etapa, também com temática da Religiosidade Afro-brasileira que o Professor e pós-graduando em Cultura Afro-Brasileira Célio Rodrigues dos Santos, Babalorixá do Núcleo de Cultura Afro-brasileira - IYA OGUM - TÊ, trabalhou sobre Diáspora Africana, destacando principalmente suas semelhanças e contribuições, tendo como foco os aspectos da religiosidade, oportunizando os cursistas conhecer a História dos Candomblés como também da Umbanda.

No decorrer do curso, de 60 horas, foram realizadas duas Aulas de Campo, uma na Escola Zumbi dos Palmares que já desenvolve um trabalho voltado para a Diversidade Étnico-Racial, ou seja, que já trabalha a Lei 10.639/03 no seu Currículo Escolar, os cursistas foram levados para analisarem a temática abordada no curso com a realidade da Escola, tendo sido muito proveitoso, destaca-se também que professores desta escola participaram da citada formação, inclusive a Diretora Geral, que vem trabalhando com intensidade a temática da Diversidade Étnico-Racial. A outra aula de campo foi para conhecer duas casas religiosas, visando aprofundar melhor o conhecimento sobre a religiosidade da Umbanda e do Candomblé. Em relação a Umbanda conheceram o Centro Espírita Umbandista OGUM / NAJÉ e do Candomblé o Núcleo de Cultura Afro brasileira IYA OGUM - TÊ. Foram enriquecedores os vários depoimentos dos cursistas, que tinham muito medo de entrar em uma casa religiosa de matriz africana, devido a sua formação anterior trazer ranços preconceituosos em relação à religiosidade de Candomblé e Umbanda. Nesta aula de campo os cursistas tiveram oportunidade para tirarem suas dúvidas e conhecerem os símbolos e ritos que expressam a religiosidade umbandista e candomblecista. Ficou claro também a diferença entre o Candomblé e a Umbanda como também suas práticas religiosas. O professor que trabalhou a temática acompanhou a aula de campo tentando fazer um paralelo entre a teoria e a prática.

Com relação ao Seminário de 40 horas cujo título foi Ações Afirmativas e a construção de uma educação anti-racista: a escola respeitando a sua diversidade na construção de identidades, contou-se com a participação do Professor Doutor em Educação Moisés de Melo Santana e da Professora Mestra Educação Brasileira Maria Alcina Ramos de Freitas, que discutiram com o grupo de professores cursistas as Políticas Públicas de Ações afirmativas numa perspectiva de construção de uma Educação antiracista. Como metodologia de trabalhos, os mesmos foram desenvolvidos dialogicamente em três Blocos temáticos: 1. Ações Afirmativas e teorias raciológicas com a exibição de Documentário sobre Relações Raciais e educação; 2. Diversidade Cultural Humana com trabalho desenvolvido em grupos e apresentação dos mesmos em Discussão Sistematizadora Coletiva; 3. Educação numa perspectiva transcultural dialógico-crítica.

Em relação às Oficinas as mesmas foram realizadas com as seguintes temáticas: Práticas pedagógicas na construção da identidade; A religiosidade afro-brasileira; Reconhecimento e valorização da arte da matriz africana como patrimônio cultural brasileiro; Influência das línguas africanas no 
português brasileiro; Quilombos; Práticas pedagógicas na construção da identidade etnomatemática e Análise e Reflexões acerca de novos materiais didáticos ligados a área afro-cultural.

$\mathrm{Na}$ Oficina, Práticas pedagógicas na construção da identidade, ministrada pela Professora Mestra em Educação Brasileira Maria Alcina Ramos de Freitas, a mesma trabalhou com os professores cursistas a produção coletiva de material pedagógico, com os seguintes aspectos abordados: Continente Africano, Diversidade, Religiosidade, Colonização e Interdisciplinaridade, tendo como metodologia, o trabalho em equipe.

Na Oficina, A religiosidade afro-brasileira, ministrada pelo Professor Mestre em Teoria Literária Lepê Correia, teve como metodologia, a exposição e reflexão junto com os professores cursistas aspectos gerais da Religiosidade Africana, fazendo um aporte teórico-filosófico das demais matrizes religiosas comparando-as com a matriz africana.

$\mathrm{Na}$ Oficina, Reconhecimento e valorização da arte da matriz africana como patrimônio cultural brasileiro, ministrada pelo Professor e especializando-se em Docência do Ensino Superior Amaurício de Jesus, o mesmo trabalhou com os professores cursistas as seguintes temáticas: 0 que é identidade cultural; Elementos da cultura afros que foram absorvidos no nosso dia a dia; Promovendo ações afirmativas na sala de aula; Registro da cultura material e imaterial local; construção de uma identidade afro-alagoana. O funcionamento da oficina partiu da intenção de levar o corpo docente a vivenciar experiências que contribuíssem para uma sensibilização, reconhecimento e produção, utilizando como eixo de ação, elementos e temas do nosso cotidiano, tais como brinquedos, festas, manifestações, hábitos, aromas e outros, sempre levando em conta a visão africana.

$\mathrm{Na}$ Oficina Influência das línguas africanas no português brasileiro, ministrada pela Professora Doutora em Antropologia Rachel Rocha de Almeida Barros, a mesma abordou os seguintes subtemas: Racismo à Brasileira; Cultura Afro-Brasileira, um universo multireferenciado e Presenças 'invisíveis' da África entre nós, tendo como metodologia a exposição e diálogo com os professores cursistas em relação aos conteúdos trabalhados.

$\mathrm{Na}$ Oficina Quilombos, ministrada pela Professora Mestra em Geografia Maria Ester Ferreira da Silva, a mesma abordou as concepções de quilombos e diversidade cultural que tem norteado reflexões educativas contemporâneas dentro da Antropologia, bem como as correntes da Geografia que melhor propiciam um conhecimento sólido para esta nova questão que se apresenta dentro da sala de aula, que a aplicabilidade da Lei 10639 no ensino da geografia. As atividades tiveram um caráter interdisciplinar porque se entende que ao discutir a questão dos quilombos faz-se necessário um profundo diálogo com a História bem como com o Ensino Religioso, Literatura, Língua Portuguesa Artes e Antropologia. 0 Material utilizado nas oficinas foi: Textos, filmes, entrevistas, recital. (Manifesto Sururu) e música. A metodologia utilizada foi estabelecida à priori pela formadora, mas devidamente alterada pelos 
professores cursistas em alguns itens que julgaram ser necessário, como por exemplo, a discussão sociológica de onde vem o nosso aluno? Culminando na discussão de uma película sobre a estrutura da sociedade hoje e de como o discurso do professor bem como o conteúdo aplicado em sala de aula não atende e nem entende o aluno hoje, porque exatamente desvinculado de todo um constructo ideológico à parte do cotidiano dos nossos alunos.

Na Oficina Práticas pedagógicas na construção da identidade etnomatemática, ministrada pela Professora Mestre em Psicologia Cognitiva Lúcia Cristina Silveira Monteiro, a mesma abordou os seguintes subtemas: Etnomatemática, um projeto de pesquisa; Matemática uma construção humana; Os números e seus significados, proporcionalidade uma idéia fundamental; Transposição didática e Etnomatemática, Modelagem na construção civil; Explorando situações geométricas para modelar, $A$ decomposição do cubo; A pesquisa em Educação Matemática, construção do conhecimento e linguagem geométrica; A pesquisa em Educação Matemática.

Na Oficina Análise e Reflexões acerca de novos materiais didáticos ligados a área afro-cultural, ministrada pelo Professor Mestre em História do Brasil Zezito de Araújo, o mesmo abordou sobre a diversidade de materiais didáticos relativo à cultura afro-brasileira, como livros didáticos e para-didáticos, vídeos-documentários, músicas..., que podem ser utilizados pelos professores no processo de ensinoaprendizagem.

\section{A DIVERSIDADE ÉTNICO-RACIAL PROMOVENDO A INTERDISCIPLINARIDADE ATRAVÉS DE PROJETOS DIDÁTICOS}

\section{O curso A Diversidade Étnico-Racial promovendo a Interdisciplinaridade através de}

Projetos Didáticos foi estruturado dentro do Projeto de Formação Continuada desta Secretaria, sendo organizado em duas etapas. Na primeira etapa ( $1^{\circ}$ semestre) foram desenvolvidas discussões e reflexões teóricas, acerca das seguintes temáticas: Interdisciplinaridade, Projetos de Trabalhos, segundo Hernandez, Fazenda, Santomé e outros teóricos, Planejamentos Interdisciplinares por eixo temáticos. $\mathrm{Na}$ segunda etapa ( $2^{\circ}$ semestre), foram realizadas práticas pedagógicas, através das seguintes oficinas por disciplinas.

A primeira foi à oficina de Artes, com a discussão sobre os antigos carnavais de Maceió e a influência africana no mesmo, com leitura do texto de Cavalcanti, "Bons e Sacudidos" - O Carnaval Negro e seus impasses em Maceió, sendo seu ponto culminante a confecção de máscaras carnavalescas.

Na segunda foi realizada a oficina de Geografia com a exibição do documentário: Bate papo com Milton Santos de Silvio Tendler, em seguida a discussão sobre a Lei 10.639/2003 e o ensino da Geografia no Brasil abordando a sua espacialidade nos aspectos regionais, sociais e econômicos dando ênfase à 
diversidade étnico-racial e concluindo com a produção de manchetes sobre temáticas da disciplina, resultando daí, na capa de um jornal geográfico.

A oficina de Ensino Religioso foi a terceira a ser realizada com a seguinte temática, $A$ Diversidade Religiosa no Cotidiano Escolar, através da dinâmica da Colcha de Retalhos, levando assim a reflexão sobre a importância da diversidade religiosa presente no contexto escolar; Leitura coletiva do texto: a Feira Mundial das Religiões de Anthony de Mello levando o grupo a uma discussão sobre 0 fenômeno religioso numa perspectiva das diversas matrizes religiosas; seguida pela apresentação de slides sobre a base legal do Ensino Religioso fundamentada no artigo 33 da lei 9.475/97 que altera a lei 9.394/96 onde a disciplina deve ser trabalhada respeitando à diversidade religiosa e combatendo 0 proselitismo, essa discussão trouxe presente outros marcos legais como a Constituição Federal de 1988, o Fórum Nacional Permanente do Ensino Religioso, a Declaração Universal dos Direitos Humanos de 1948, bem como a produção de uma notícia de jornal a partir de um fato real ou imaginário ocorrido em uma escola.

A última oficina realizada foi a de História, que teve como tema, $A$ Desconstrução da Discriminação no Livro Didático de Ana Célia da Silva, a exibição do documentário: Heróis de Todo Mundo da Cor da Cultura, o uso de biografias de personagens negros através de textos fatiados e lacunados e como encerramento, leitura do poema de Bertolt Brecht: Perguntas de Operário Letrado.

No penúltimo encontro, houve a socialização das ações desenvolvidas nas escolas, através das orientações pedagógicas feitas por este Núcleo, durante a Formação Continuada de 2008.

Vários docentes, nas diversas modalidades de ensino dos três turnos, mostraram através de comunicação oral, as suas práticas pedagógicas pautadas numa perspectiva da diversidade e interdisciplinaridade.

Houve a participação da técnica da equipe da coordenação da formação, professora mestra Mônica Regina dos Santos com o seguinte tema o papel da interdisciplinaridade no currículo, levando o grupo a refletir sobre as concepções de sociedade e sujeito trazidas pelas abordagens explicativas da pós-modernidade e do marxismo.

No último encontro iniciamos com a música Paciência de Lenine e Dudu Falcão levando os participantes a refletirem sobre a importância das nossas atividades, mas levando em consideração que a vida não para. Em seguida os cursistas fizeram uma avaliação pessoal sobre a formação do NEDER e partilhamos os pontos que para eles seriam relevantes, principalmente as propostas para 2009. Logo depois tivemos um momento de Biodança com a Professora Amélzia Maria da Soledade Dias e culminamos este encontro com uma confraternização em cada turma. 


\section{CURRÍCULO ESCOLAR E DIVERSIDADE ÉTNICO-RACIAL PROMOVENDO: A INTERDISCIPLINARIDADE NA ESCOLA}

O curso Currículo Escolar e Diversidade Étnico-Racial promovendo: a Interdisciplinaridade na Escola foi estruturado dentro do Projeto de Formação Continuada desta Secretaria, foram desenvolvidas discussões e reflexões teóricas, acerca das seguintes temáticas: Diversidade Étnico-Racial, Interdisciplinaridade, Currículo Escolar.

Em relação aos encontros, tivemos um total de 14 encontros, sendo realizada uma aula de campo à Comunidade Indígena Xucurus-Kariris do município de Palmeiras dos Índios.

No primeiro encontro tivemos como pauta: Acolhida: A História do Arco-Íris; Apresentação do Plano de Formação e sugestões para 2009; Dinâmica das Questões Geradoras: Qual o seu pertencimento étnico: branco, afrodescedentes, indígena ou outro? Você já sofreu alguma discriminação étnica? Você é preconceituoso ou racista? O Brasil é um país preconceituoso ou racista? Por que a cultura branca é (considerada) superior às culturas dos demais grupos étnicos? Você acha que a sociedade brasileira tem uma dívida social para com os negros e indígenas? Você sabe a diferença entre raça e etnia? Debate.

No segundo encontro tivemos como pauta: Acolhida: Dinâmica - Como conviver com 0 diferente; Apresentação das Diretrizes Curriculares; Trabalho em grupo: Leitura do texto, destacando as idéias centrais do texto; Questão norteadora: 0 que o texto mim diz? Trabalho em grupos: tema: pontos apresentados nas diretrizes. Grupos: 1. Zumbi - Questões introdutórias e Políticas de reparações, de reconhecimento e valorização, de ações afirmativas; 2. Dandara - Educação das relações, caráter normativos que seguem; 3. Acotirene - História e cultura Afro-Brasileira e Africana: Determinações, Consciência Política e História da Diversidade e Fortalecimento de Identidades e Direitos; 4. Mãe Netinha - Ações Educativas de Combate ao Racismo e Discriminações; 5. Tia Marcelina - Sistema de Ensino e os Estabelecimentos de Educação Básica e Obrigatoriedade do Ensino de História e Cultura AfroBrasileiras, Educação das Relações Étnico-Raciais e os Conselhos de Educação.

No terceiro encontro tivemos como pauta: Acolhida: Mafalda em Quadrinhos Animados; Reflexão sobre a Acolhida; Exibição do Vídeo: Os Currículos Escolares e a 10.639/2003; Indagações sobre Currículo - Diversidade e Currículo por Nilma Lino Gomes (Slides); Debate; Encaminhamentos: Questões sobre o Currículo e Informes.

No quarto encontro tivemos como pauta: Acolhida: Slides com a música: Ninguém é igual a ninguém; Trabalho em grupo sobre as indagações do encontro anterior; Socialização dos grupos; Exibição do documentário: Rompendo o Silêncio Debate. 
No quinto encontro tivemos como pauta: Acolhida: Vídeo Ídolos com Susan Boyle; Retomada do encontro anterior; Exibição do documentário: Olhos Azuis; Discussão do Documentário.

No sexto encontro tivemos como pauta: Acolhida: Clipe da Música Black our White de Michael Jackson; Retomada do encontro anterior; Relatos de Casos; Plano de Intervenção; Divulgação da I Amostra.

No sétimo encontro tivemos como pauta: Acolhida: Tratado de Paz; Retomada do Encontro Anterior; Leitura de Imagens dos Curtas; Retomada do Plano de Intervenção; Encaminhamento da Formação.

No oitavo encontro tivemos como pauta: Acolhida - Dinâmica: a) Redação em corrente b) Desenho Cooperativo; Trabalho em grupo por disciplina; Apresentação dos trabalhos em grupo com intervenção das diversas áreas; Retomada do plano de intervenção; Esclarecimentos sobre a aula de campo para uma comunidade Indígena; Conclusão.

No nono encontro tivemos como pauta: Acolhida: Quem são os índios para você? Índios em Alagoas - Informes gerais para a aula de campo (Povos Xukuru-Kariri - Palmeira dos Índios); Exibição dos documentários: Índio no Brasil - Episódio 1 Debate/ comentário.

No décimo encontro tivemos como pauta: Acolhida: historia Brasileira da Infâmia (Parte 1) de Werner Sales; Atividades sobre o Documentário: Quais as propostas de atividades você trabalharia com seus alunos e alunas? Construção de um roteiro para aula de campo; Apresentação dos grupos (Roteiro); Conclusão.

No décimo primeiro encontro tivemos como pauta: Acolhida: Dança; Reflexão da dinâmica; Exposição oral das culturas e artes dos povos da nossa matriz cultural; Oficina de arte visuais abordando as características artísticas desses povos; Exposição do material construindo e comentários. Avaliação do encontro.

No décimo segundo encontro - Aula de Campo - Roteiro para a aula: EQUIPE 1 - Dados Gerais: 1. O senhor poderia falar um pouco sobre a origem dessa comunidade? 2. 0 que significa Xucuru-Kariri? 3. Quantas pessoas vivem nessa comunidade? 4. De que vocês se sustentam? 5. As mulheres também trabalham? EQUIPE 2 - Música e Dança: 1. Como vocês vêm à dança e a musica? 2. Vocês usam a música conforme a dança? 3. Existem músicas específicas para cada momento ou elas podem ser cantadas e dançadas todos os momentos? 4. Quem faz as músicas? 5. Quais os instrumentos usados? 6. Quem faz os instrumentos? 7. As danças são demonstradas como ritos ou como diversão? Ou as duas? EQUIPE 3 - Rituais: 1. Quais são as expressões religiosas dessa comunidade? 2. Vocês podem relatar? EQUIPE 4 - Cura: 1. Quando as pessoas adoecem como é feito o tratamento ou a cura? 2. Quais são as ervas e para que servem? EQUIPE 5 - Vestes: 1. Existem vestimentas especificas para 
cada momento? 2. Quem faz? 3. Quem pode usar? 4. Quais as cores que vocês usam para pintura e o que significa? EQUIPE 6 - Terra: 1. Como está a regularização da posse de terra? 2. A terra reivindicada é suficiente para sustentação e manutenção de toda comunidade? 3. Qual a relação que vocês fazem com 0 trabalho do CIMI e da FUNAI? EQUIPE 7 - Educação Escolar: 1. Existe alguma escola na comunidade? 2. Ate que serie? 3. Quem são os professores?

No décimo terceiro encontro tivemos como pauta: Acolhida- Música: Inclassificáveis. Relatos da aula de campo sobre a comunidade Indígena em Palmeira dos Índios no dia 07/11/09, focando a Interdisciplinaridade. Avaliação da Formação Continuada do NEDER/2009. Breves comentários sobre 0 material recebido para I Mostra sobre a Diversidade. Confraternização.

\section{CONSIDERAÇÕES FINAIS}

O silêncio escolar sobre o racismo cotidiano não só impede o florescimento do potencial intelectual de milhares de mentes brilhantes nas escolas brasileiras, tanto de alunos negros quanto de brancos, como também nos embrutece ao longo de nossas vidas, impedindo-nos de sermos seres realmente livres "para ser o que for e ser tudo" - livres dos preconceitos, dos estereótipos, dos estigmas, entre outros males. Portanto, como professores(as) ou cidadãos(ãs) comuns, não podemos mais nos silenciar diante do crime de racismo no cotidiano escolar, em especial se desejamos realmente ser considerados educadores e ser sujeitos de nossa própria história.

Em estudos anteriores, foi possível comprovar que a existência do racismo, do preconceito e da discriminação raciais na sociedade brasileira e, em especial, no cotidiano escolar acarretam aos indivíduos negros: auto-rejeição, desenvolvimento de baixa auto-estima com ausência de reconhecimento de capacidade pessoal; rejeição ao seu outro igual racialmente; timidez, pouca ou nenhuma participação em sala de aula; ausência de reconhecimento positivo de seu pertencimento racial; dificuldades no processo de aprendizagem; recusa em ir à escola e, conseqüentemente, evasão escolar. Para o aluno branco, ao contrário acarretam: a cristalização de um sentimento irreal de superioridade, proporcionando a criação de um círculo vicioso que reforça a discriminação racial no cotidiano escolar, bem como em outros espaços da esfera pública.

Não há como negar que o preconceito e a discriminação raciais constituem um problema de grande monta para a criança negra, visto que essa sofre direta e cotidianamente maus tratos, agressões e injustiças, os quais afetam a sua infância e comprometem todo o seu desenvolvimento intelectual. A escola e seus agentes, os profissionais da educação em geral, têm demonstrado omissão quanto ao dever de respeitar a diversidade racial e reconhecer com dignidade as crianças e a juventude negra. 
O racismo e seus derivados no cotidiano e nos sistemas de ensino não podem ser subavaliados ou silenciados pelos quadros de professores(as). É imprescindível identificá-los e combatêlos. Assim como é pungente que todos(as) os(as) educadores(as) digam não ao racismo e juntos promovam o respeito mútuo e a possibilidade de se falar sobre as diferenças humanas sem medo, sem receio, sem preconceito e, acima de tudo, sem discriminação.

No cotidiano escolar, considerável parcela de profissionais da educação diz não perceber os conflitos e as discriminações raciais entre os próprios alunos e entre professores e alunos. Por esse mesmo caminho, muitos também não compreendem em quais momentos ocorrem atitudes e práticas discriminatórias e preconceituosas que impedem a realização de uma educação anti-discriminatória. Porém, um olhar um pouco mais atento e preocupado com as relações estabelecidas na escola flagra situações que constatam a existência de um tratamento diferenciado que hierarquiza o pertencimento racial dos alunos. Essa diferenciação de tratamento, uma atitude anti-educativa, concorre para a difusão, a reprodução e a permanência do racismo no interior das escolas e na nossa sociedade como um todo.

O conflito e a discriminação raciais na escola não se restringem às relações interpessoais. Os diversos materiais didático-pedagógicos - livros, revistas, jornais, entre outros - utilizados em sala de aula, que, em geral, apresentam apenas pessoas brancas com e como referência positiva, também são ingredientes caros ao processo discriminatório no cotidiano escolar. Quase sem exceção, os negros aparecem nesses materiais apenas para ilustrar o período escravista do Brasil - Colônia ou, então, para ilustrar situações de subserviência ou de desprestígio social. A utilização de recursos pedagógicos com esse caráter remonta a um processo de socialização racista, marcadamente branco-eurocêntrico e etnocêntrico, que historicamente enaltece imagens de indivíduos brancos, do continente europeu e estadunidense como referências positivas em detrimento dos negros e do continente africano.

Afora isso, há outros fatores que, outrossim, favorecem a interiorização/cristalização de idéias preconceituosas e atitudes discriminatórias contra os(as) alunos(as) negros(as). Dissimulações, apelidos, xingamentos, ironias consolidam a perpetuação de preconceitos e discriminações raciais latentes. Situações nas quais estudantes negros(as) são tratados(as) por seus colegas e/ou professores(as) com termos preconceituosos e discriminatórios sinalizam a reiterada prática de investida contra a humanidade dos primeiros, numa tentativa de transformá-los em animais irracionais ou coisas, não sujeitos sociais: "urubu", "macaco", "picolé de asfalto", "a coisa está preta", "humor negro", "carvãozinho", "filhote de cruz-credo", etc.

Todos os profissionais da educação que favorecem consciente ou inconscientemente a manutenção, a indução ou a propagação de racismo, preconceitos e discriminação raciais no espaço escolar devem ser questionados e se auto-questionar quanto ao exercício de sua profissão de educador. Buscar soluções para esses problemas não é um trabalho apenas em favor dos(as) alunos(as) 
negros(as), representa um trabalho em favor de todos(as) os(as) brasileiros(as), quer sejam pessoas pretas, pardas, indígenas, brancas ou amarelas.

Uma educação anti-racista não só proporciona o bem-estar do ser humano, em geral, como também promove a construção saudável da cidadania e da democracia brasileiras.

Portanto, nós, educadores(as) brasileiros(as), necessitamos urgentemente contemplar no interior das escolas a discussão acerca das relações raciais no Brasil, bem como de nossa diversidade racial. Nessa linha, é preciso não só boa vontade e sensibilidade dos profissionais da educação, mas também o fornecimento de material didático-pedagógico anti-racista e recursos auxiliares aos professores para que possam ministrar aulas combatendo o preconceito e a discriminação raciais. É com essa intenção que o Núcleo de Estudos e Pesquisa sobre a Diversidade Étnico-Racial (NEDER), publica este texto. Trata-se apenas de um dos instrumentos - não mais nem menos importante que outros - na luta anti-racista no cotidiano escolar. Esse esforço irá no sentido de contribuir para que se construa uma educação inclusiva, livre de preconceitos, democrática e não etnocêntrica.

A Secretaria Municipal de Educação de Maceió tem empreendido esforços na melhoria da qualidade do ensino, destacando principalmente a Formação Continuada dos profissionais da Educação, visando garantir aos mesmos a formação no decorrer do desempenho de suas funções pedagógicas (técnicas, administrativas e de docência) para assim evoluírem qualitativamente no que diz respeito a suas posturas metodológicas e ações pedagógicas na unidade de ensino e na sociedade, objetivando melhorias em suas práticas educativas.

O objetivo maior desse Núcleo está sendo o direcionamento de ações na Rede Municipal de Ensino de Maceió, orientando-as e apoiando-as a partir do reconhecimento das raízes do passado histórico brasileiro que levaram à exclusão social de negros e índios, sem esquecer a fomentação de espaços de debate, reflexão e pesquisa sobre a diversidade étnico-racial, que favoreçam a conscientização de educadores (as) quanto às diferenças étnico-raciais existentes na sociedade.

\section{REFERÊNCIAS}

1. BRASIL, Secretaria de Educação Fundamental (1997). Parâmetros Curriculares Nacionais: Pluralidade Cultural, Orientação Sexual. Secretaria de Educação Fundamental. Brasília: MEC/SEF.

2. BRASIL, Educação anti-racista: caminhos abertos pela Lei Federal $n^{0}$. 10.639/03. Secretaria de Educação Continuada, Alfabetização e Diversidade (SECAD). Brasília: Ministério da Educação, Secretaria de Educação Continuada, Alfabetização e Diversidade, 2005.

3. BRASIL. Orientações e Ações para a Educação das Relações Étnico-Raciais. Ministério da Educação. Secretaria de Educação Continuada, Alfabetização e Diversidade, SECAD, 2006. 
4. BRASIL. Plano Nacional de Implantação das Diretrizes Curriculares Nacionais para Educação das Relações Étnico-Raciais e para o Ensino de História e Cultura Afro-brasileira e Africana. Ministério da Educação. Brasília, 2009.

5. CUNHA Jr., Henrique (1996). As estratégias de combate ao racismo. Movimentos negros na escola, na universidade e no pensamento brasileiro. In: MUNANGA, Kabengele (org.). Estratégias e Políticas de Combate à Discriminação Racial, São Paulo: Edusp, p.147-156.

6. FAZENDA, Ivani Catarina Arantes. Integração e interdisciplinaridade: uma análise da legislação do ensino brasileiro de 1961 a 1977. (Tese de Mestrado). São Paulo, PUCSP, 1978. 111p.

7. McLAREN, P. (2000). Multiculturalismo Revolucionário: pedagogia do dissenso para o novo milênio. Porto Alegre: Ed. Artmed, p.293.

8. MUNANGA, Kabengele (org.) (1996). Estratégias e Políticas de Combate à Discriminação Racial, São Paulo: Edusp.

9. JAPIASSÚ, Hilton. Interdisciplinaridade e patologia do saber. Rio de Janeiro, Imago, 1976. 220p.

Artigo recebido em: 29/07/2010

Aprovado em: 03/09/2010 